\title{
Encyclopedia of Electronic HRM
}

Edited by

Tanya Bondarouk and Sandra Fisher

\section{DE GRUYTER}


ISBN 978-3-11-062899-9

e-ISBN (PDF) 978-3-11-063370-2

e-ISBN (EPUB) 978-3-11-062998-9

Library of Congress Control Number: 2020939277

Bibliographic information published by the Deutsche Nationalbibliothek

The Deutsche Nationalbibliothek lists this publication in the Deutsche Nationalbibliografie; detailed bibliographic data are available on the Internet at http://dnb.dnb.de.

(c) 2020 Walter de Gruyter GmbH, Berlin/Boston Cover image: slavemotion/E+/gettyimages.de Typesettung: Integra Software Services Pvt. Ltd. Printing and Binding: $\mathrm{CPI}$ books $\mathrm{GmbH}$, Leck

www.degruyter.com 


\section{Contents}

Sandra L. Fisher and Tanya Bondarouk

Introduction $-\mathbf{V}$

\section{Part 1: Basics of e-HRM}

Julio Canedo

Strategic Electronic Human Resource Management —3

Richard D. Johnson

Human Computer Interaction and HRIS - 8

Stefan Strohmeier

HR Digitalisation Technologies -14

Sebastian Marin and Richard Landers

Gamification in e-HRM 20

Valentina Battista and Emma Parry

Social Media and Human Resource Management — 27

\section{Part 2: Context of e-HRM}

Emma Parry and Hilla Peretz

Organizational Outcomes and e-HRM -35

\section{Rita Bissola}

Industry 4.0 and e-HRM -40

Huub Ruël

e-HRM goals, Types and Outcomes in e-HRM Innovation - 47

Stefan Strohmeier

Algorithmic Decision Making in HRM -54 


\section{Part 3: Organizational Issues in e-HRM}

Tanya Bondarouk

Implementation of e-HRM: Definitions and Theoretical Approaches - 63

Sandra L. Fisher

Organisational Change in the Context of e-HRM -70

Guido Hertel, Sarah M. Meeßen, and Miriam Höddinghaus

Trust in the Context of e-HRM -76

Barbara Imperatori

Implications of e-HRM for the Role of Employees — 82

Tanya Bondarouk

Employer Branding and Social Media — 90

Anna B. Holm

Virtual HRM and Virtual Organizing — 95

Rita Bissola

Design Thinking and Implications for Organizational Design - 99

\section{Part 4: Theoretical Viewpoints}

Anna B. Holm

Institutional Theory Perspective 109

Alessandra Lazazzara and Eleanna Galanaki

Resource-Based View Perspective in e-HRM Research — 117

\section{Part 5: Social Issues of e-HRM}

Jamie A. Gruman and Alan M. Saks

e-Socialization -125

Surinder Kahai

e-Leadership — 131 
Stefan Strohmeier

Sustainable Electronic HRM 138

Sharna Wiblen

Talent Management and Digitalised Talent Management - 144

Debora Jeske and Thomas S. Calvard

Risk Management in the Age of e-HRM -150

Michael E. Wasserman and Sandra L. Fisher

Sailing in Stormy Weather: Digitalization, Ethics and e-HRM — 156

Debora Jeske

Introducing e-Internships -163

\section{Part 6: Functional Areas of e-HRM}

Andrea R. Neely and John L. Cotton

e-Mentoring — 171

Anthony S. Boyce and Christine E. Boyce

Talent Identification in the Digital Age: Moving from Selection

to e-Selection -176

Stefan V. Dumlao, Anjelica M. Mendoza, and Stephanie C. Payne

Performance Monitoring in the 21st Century — 182

Michael E. Wasserman and Sandra L. Fisher

e-Learning - 188

Anna B. Holm

e-Recruiting - 195

Stephanie C. Payne and Anjelica M. Mendoza

e-Performance Management -202

Sladjana Nørskov and John P. Ulhøi

The Use of Robots in Job Interviews — 208 
Anna B. Holm

Applicant Tracking Systems -214

Christopher J. Hartwell and Regan Eggli

Social Media Screening in Employee Selection - 220

\section{Part 7: Serving Different Audiences}

Emma Parry

Generations - 231

Jeroen Meijerink

Gig Work and Online Labour Platforms' Use of e-HRM 237

Miguel R. Olivas-Luján, M-Y. Yusliza, and Sergio Madero-Gómez

Emerging Markets and e-HRM -244

Jeroen Meijerink

HR Shared Services -251

\section{Part 8: Technical Issues in e-HRM}

Stefan Strohmeier

Big HR Data 259

Christine R. Scheu

General Data Protection Regulation (GDPR), Assessment, and HR Considerations -265

Elena M. Auer and Richard N. Landers

Creating Data-Driven HR Insights: Data Science in HRM -270

Daniel Shore

Cybersecurity Challenges in Protecting Human Resource Information Systems -276

Janet H. Marler

HR/People Analytics — 283 
Eleanna Galanaki and Alessandra Lazazzara

HR Metrics — 288

Miguel R. Olivas-Luján

Blockchains in HRM 293

Authors -299

List of Tables -309

List of Figures -310

Index - 311 


\section{Sandra L. Fisher and Tanya Bondarouk Introduction}

We have been working on this project for almost three years, and we are proud to offer the Encyclopedia - a unique book about electronic Human Resource Management. The world does not lack for HRM and technology books, podcasts, videos, and articles. Hundreds of researchers and business leaders produce thousands of knowledge-items about HRM and technology each year. But few dare to build bridges from the past history towards the future. That is the idea of this encyclopedia - with respect for history, grounded in research, connected with practice, but built for questions to guide future inquiries.

The field of electronic human resource management, or e-HRM, has become an important interface between people and technology in organizations. As the importance of digital technologies in the management of people has increased, so has the volume of information available about tools, processes, and theories for doing this more effectively. Our concept for this encyclopedia was to offer a valuable companion for HR researchers, HR executives, PhD candidates and students wanting to find concise definitions, summaries and debates about a plethora of terms within the eHRM field in one place. This volume includes state-of-the art contributions from leading experts in the field, who also offer their views on the future research directions. You will find here more than one hundred research questions, that each on its own can inspire a new PhD project! While there has been much discussion about the definition of e-HRM and how it differs from related concepts such as human resource information systems (HRIS) and virtual HR (Florkowski, 2018), we treat eHRM inclusively in this encyclopedia, including a wide range of topics that touch on this use of digital tools to manage people both now and in the future. An earlier encyclopedia (Torres-Corronas \& Arias-Olivas, 2008) explicitly tied together HRIS and e-HRM, and this volume strives to provide an updated viewpoint on many of those topics.

\section{Brief History of e-HRM}

The field of e-HRM has developed significantly over the past 20 years, becoming a legitimate area of study and practice within broader human resource management. One artifact of this development is the Sierra-Cedar industry survey, now in its 22nd year of tracking organisational-level adoption of HR technologies. Started in 1997 by the Hunter Group as a survey on HR self-service technologies, the survey has grown substantially in both breadth of coverage and number of respondents and has provided researchers and practitioners with an effective gauge of changes in the field. 
The presence of the international conference on e-HRM is another indication of growth and development in the field. International researchers in e-HRM started a biannual conference series in 2006, allowing researchers to gather in a venue promoting the exchange of the latest research findings in the field, mixing with business leaders and consultants to ensure the connection with practice. Conference locations have included the Netherlands, the United Kingdom, France, Germany, the United States, Italy, and Denmark. The conference started expanding beyond a tight definition of e-HRM to include concepts of digital HRM in 2016, Industry 4.0 in 2018, and digitalized organizations and ecosystems in 2020. We also see many sessions on e-HRM topics at mainstream international conferences in management and I/O psychology, such as the Academy of Management Meetings, the Society for Industrial/Organizational Psychology, and the European Association of Work and Organizational Psychology.

There have been no fewer than ten special issues of peer reviewed journals focusing on e-HRM research in the past 15 years (Bondarouk, Ruël \& Parry, 2017), starting with a special issue of Human Resource Management on e-HR in 2004. These special issues have addressed topics such as value creation, workforce management, e-HRM in a multinational or cross-national context, and the transformation of the HR function. These special issues have helped to promote the development of an emerging field, placing special attention on publication opportunities for authors in related areas. Similarly, a number of edited books examining e-HRM have been published throughout the years, some as an outgrowth of the international e-HRM conferences (e.g., Bissola \& Imperatori, 2019; Bondarouk, Ruël \& Parry, 2017) and others as part of a professional book series (e.g., Bondarouk, Ruël, \& Looise, 2011; Gueutal \& Stone, 2005). These books have helped move the field forward by publishing accessible volumes of recent research, providing detailed information on selected topics. We have also seen publication of textbooks on e-HRM, with Kavanaugh, Thite and Johnson (2012) as an example of an early text blending HRIS and HR practices, and Thite (2018) specifically addressing e-HRM. There has also been development of academic study programs at multiple universities allowing students to focus their studies on this intersection of HRM and technology. And, by 2020, there have been more than twenty PhD projects dedicated to a topic within eHRM.

With all of these developments, we believed it was time to assemble this encyclopedia to recognize and further promote formalization and institutionalization of the academic field of e-HRM. Many of the contributors to this encyclopedia noted that the science behind application of technology to HRM is lagging behind the practice. This offers great opportunity to researchers to conduct research that will test and evaluate the many ways in which e-HRM is already in use, making recommendations for the effective and ethical application of technology to managing people in organisations. 


\section{Interdisciplinary and Diverse}

One of our goals with this encyclopedia was to integrate contributions about e-HRM from different disciplines like Information Systems, Computer Sciences, Design Sciences, Decision Science, Organizational Behavior, Human Resource Management, and Industrial/Organizational (Work) Psychology, demonstrating the interdisciplinary nature of the research. This is reflected in the wide range of theories applied, published works cited, and perspectives taken. The 42 different authors of the entries are diverse in other respects as well. Given the practical nature of the topic we have a mix of academic researchers and practitioners represented. The academic researchers are working in schools of business or management, and departments of psychology, economics, industrial engineering, social and political science, management information systems, and business development and technology. The practitioners include both consultants and industry representatives. The authors also represent the global nature of the e-HRM field, with authors from 14 different countries.

\section{Overview of the Entries}

There are 47 entries in the encyclopedia. Many of them represent specific systems with which HR professionals or employees might interact, such as recruiting, selection, performance management, talent management, socialization, mentoring, and e-learning. These systems have formed the backbone of e-HRM research and application. Entries in this section address the foundational components of such functional areas and look forward to how such systems are changing to leverage new technologies and support emerging HR needs.

Other entries focus on specific theories underpinning some of the research. These theoretical approaches include institutional theory, resource-based view of the firm, and human computer interaction. Other key theories used in e-HRM research, such as those related to trust, communication, person-organisation fit, and leadership, are described in entries found in other sections of the encyclopedia.

The next section examines organizational level issues in the implementation of eHRM. Here authors consider the strategic nature of e-HRM and various organizational goals for the use of e-HRM systems. One common framework looks at operational, relational, and transformational outcomes of e-HRM systems, with transformational outcomes generally defined as those of a strategic nature. This has been a key debate in the e-HRM literature since Marler and Fisher (2013) noted there was little empirical evidence that e-HRM makes the HR function more strategic. Factors related to this debate and the overall contribution of e-HRM to organizational functioning are discussed further in this section and will doubtless continue to be an important point of discussion moving forward. 
Another group of entries addresses various contexts within which e-HRM is used. This section includes entries on generational differences, emerging economies, the gig economy, and Industry 4.0. These entries examine ways in which the specific context in which the technology is used offers both opportunities and limitations for the application of e-HRM. For example, developments in the online gig economy require development of new ways to manage workers through technology, while Industry 4.0 challenges HRM to increase digitalization and support new characteristics of work.

Entries in the next section address how e-HRM affects work that is performed within the HR function, both what kind of work is performed and how it is accomplished. These entries address shared service centers, the role of employees in HR work and how e-HRM facilitates co-creation, the use of HR metrics in driving and assessing HR practices, and the role of HR analytics in the modern HR function. Without a doubt, the role of HR professionals has changed significantly due to eHRM. These entries explore some of these changes and how the HR function can continue to have a positive impact on organisations. For example, the use of data and analytics is often viewed as one route to more strategic application of e-HRM, and the authors in this section help identify key issues in this effort.

The next section focuses on underlying technological, structural and organizational issues with any e-HRM system such as trust, ethics, risk management, cybersecurity, organizational change, and legal constraints. Many of the individual entries in other sections of the volume also mention ethical concerns. Rapidly changing law regarding the use and management of employee data creates challenges for employers and consultants alike. Europe has had the strongest data protection regulations with the GDPR but other countries are enhancing legal protections for employees in ways that will likely impact use of HR data in coming years. Indeed, the 2020 implementation of new data privacy regulations in the California Consumer Protection Act also governs the use of some employee data, requiring disclosure of how data will be used. Other regulations govern the use of algorithms for employment decision making. Issues of trust, risk management, and organizational change are intertwined as employees decide how they feel about new technologies as part of their work lives and act accordingly.

Another group of entries details how foundational technology concepts originating in other disciplines are applied to emerging e-HRM practices. Here authors describe and debate how data science, big data, algorithms, gamification, robots, social media, blockchain and other concepts apply to e-HRM. HR researchers and practitioners often see these concepts in the media and may draw some intuitive but inaccurate conclusions about their application to HR practices. The entries in this section clarify, for example, what data science entails and how it is related to HRM, and if we really have Big Data in HR. Similarly, the entry on gamification clarifies how this technique is different from games, and how it can be applied to recruiting, selection, training, and performance management. The entry on digitalization technologies 
describes five core technologies (social, mobile, analytics, cloud, and internet of things) and explains how all five, known as SMACIT, are included in the study of eHRM. All five of these technologies are also addressed in other entries.

One core challenge of developing a volume such as this is keeping up with the rapid developments in technology, even between submission of the entries in 2019 and the actual publication of the book in 2020. Many of the entries specifically address the evolution (and in some cases, revolution) of technologies in their area. For example, the entry on applicant tracking systems (ATS) describes the gradual evolution of these systems from a recruiting database system to a full-service recruiting platform. Developments in augmented and virtual reality technologies affect opportunities to develop new methods for e-learning and trainee assessment, and advances in artificial intelligence are rapidly changing recruiting and selection practices. We are pleased that authors were able to offer general principles and frameworks underlying these technologies to assist the reader in better understanding the current state but also to help accommodate further developments. In the spirit of continuous development, each entry offers future research directions to provide guidance for the field. The authors have also provided their recommendations for the most important readings for learning more about each topic. We hope that all readers find the volume useful, whether you have been a part of the e-HRM community for many years or are just now joining in the journey.

\section{References}

Bissola, R. \& Imperatori, B. (Eds.) (2019), HRM 4.0 For Human-Centered Organizations (Advanced Series in Management, Vol. 23), Emerald Publishing Limited

Bondarouk, T., Parry, E., \& Furtmueller, E. (2017). Electronic HRM: four decades of research on adoption and consequences. The International Journal of Human Resource Management, 28(1), 98-131.

Bondarouk,T., Ruël, H. J. M. \& Looise, J. C. (Eds.) (2011), Electronic HRM in Theory and Practice (Advanced Series in Management, Vol 8)

Florkowski, G.W. (2018). HR Technology Systems: An evidence-based approach to construct measurement. Research in Personnel and Human Resources Management, 36, 197-239.

Gueutal, H., Stone, D. L., \& Salas, E. (2005). The Brave New World of eHR: Human Resources in the Digital Age: Wiley

Kavanagh, M.J., Thite, M. \& Johnson, R. D. (Eds.) Human Resource Information Systems: Basics, Applications \& Directions. Thousand Oaks, CA: Sage.

Marler, J., \& Fisher, S.L. (2013). An evidence based review of e-HRM and strategic human resource management. Human Resource Management Review, 23, 18-36.

Thite, M. (2018). E-HRM: Digital Approaches, Directions, and Applications. Routledge.

Torres-Corronas, T. \& Arias-Olivas, M. (Eds.) (2008). Encyclopedia of Human Resources Information Systems: Challenges in e-HRM. Hershey: IGI. 
